\title{
PORQUE EU NÃO SOU UM PSICÓLOGO COGNITIVISTA ${ }^{1}$
}

\author{
WHY I AM NOT A COGNITIVE PSYCHOLOGIST
}

\author{
B. F. SKINNER \\ HARVARD UNIVERSITY, USA
}

\begin{abstract}
RESUMO
As variáveis das quais o comportamento humano é função estão no ambiente. Nós distinguimos entre (1) a ação seletiva deste ambiente durante a evolução das espécies, (2) seu efeito em modelar e manter o repertório de comportamentos que transforma cada membro da espécie em uma pessoa e (3) sua função como ocasião na qual o comportamento ocorre. Os psicólogos cognitivistas estudam essas relações entre organismo e ambiente, mas eles raramente lidam com elas diretamente. Em vez disso, eles inventam substitutos internos que se tornam objetivo de estudo de sua ciência. Tendo mudado o ambiente para dentro da cabeça na forma de experiência consciente e o comportamento na forma de intenção, desejos, e escolhas, e tendo armazenado os efeitos das contingências de reforçamento como conhecimento e regras, os psicólogos cognitivistas colocam tudo isso junto para compor um simulacro interno do organismo, nada diferente do homúnculo clássico. $\mathrm{O}$ aparato mental estudado pela psicologia cognitivista é simplesmente uma versão bastante grosseira das contingências de reforçamento e seus efeitos. Eu não sou um psicólogo cognitivista por várias razōes. Não vejo qualquer evidência de um mundo interior de vida mental que se relacione quer com uma análise do comportamento como uma função de forças ambientais, quer com a fisiologia do sistema nervoso. O apelo para estados e processos cognitivos é um desvio de atenção que pode ser responsável por muitas de nossas falhas para resolver nossos problemas. Nós escolhemos o caminho errado já de início, quando fazemos a suposição de que nossa meta é mudar "mentes e corações de mulheres e homens". Precisamos mudar nosso comportamento e só podemos fazê-lo mudando nosso ambiente físico e social.
\end{abstract}

Palavras-chave : cognitivismo, behaviorismo, comportamento, causação

\begin{abstract}
The variables of which human behavior is a function lie in the environment. We distinguish between (1) the selective action of that environment during the evolution of the species, (2) its effect in shaping and maintaining the repertoire of behavior which converts each member of the species into a person, and (3) its role as the occasion upon which behavior occurs. Cognitive psychologists study these relations between organism and environment, but they seldom deal with them directly. Instead they invent internal surrogates which become the subject matter of their science. Having moved the environment inside the head in the form of conscious experience and behavior in the form of intention, will, and choice, and having stored the effects of contingencies of reinforcement as knowledge and rules, cognitive psychologists put them all together to compose an internal simulacrum of the organism. The mental apparatus studied by cognitive psychology is simply a rather crude version of contingencies of reinforcement and their effects. I am not a cognitive psychologist for several reasons. I see no evidence of an inner world of mental life relative either to an analysis of behavior as a function of environmental forces or to the physiology of the nervous system. The appeal to cognitive states and processes is a diversion which could well be responsible for much of our failure to solve our problems. We choose the wrong path at the very start when we suppose that our goal is to change the "minds and hearts of men and women". We need to change our behavior and we can do so only by changing our physical and social environments.
\end{abstract}

Key words: cognitivism, behaviorism, behavior, causation

As variáveis das quais o comportamento humano é função estão no ambiente. Nós distinguimos entre (1) a ação seletiva deste ambiente durante a evolução das espécies, (2) seu efeito em modelar e manter o repertório de comportamentos que transforma cada mem- bro da espécie em uma pessoa e (3) sua função como ocasião na qual o comportamento ocorre. Os psicólogos cognitivistas estudam essas relações entre organismo e ambiente, mas eles raramente lidam com elas diretamente. Em vez disso, eles inventam substitutos in-

1 Artigo originalmente publicado em 1977 na revista Behaviorism, Vol. 5, no 2, Fall, hoje Behavior and Philosophy, que autorizou a publicação da tradução. Tradução realizada por Olavo de Faria Galvão (Universidade Federal do Pará) e revisada por José Carlos Simões Fontes, em 1981. Resumos em português e inglês extraídos do texto original por Deisy das Graças de Souza; a publicação original não incluía resumo. 
ternos que se tornam objetivo de estudo de sua ciência.

Tome-se, por exemplo, o tão falado processo de associação. No experimento de Pavlov um cão faminto ouve uma campainha e então é alimentado. Se isto ocorre muitas vezes, o cão começa a salivar quando ouve a campainha. $\mathrm{O}$ padrão de explicação mentalista é de que o cão "associa" a campainha com a comida. Mas foi Pavlov quem as associou! "Associar" significa juntar ou unir. O cão meramente começa a salivar ao ouvir a campainha. Não temos evidência alguma de que ele o faça assim por causa de um equivalente interno das contingências.

$\mathrm{Na}$ "associação de idéias" as idéias são réplicas internas de estímulos, ao que retornarei adiante. Se nós já comemos limões, podemos sentir o gosto de limão ao ver um limão ou ver um limão ao saborear suco de limão, mas não fazemos isso porque associamos o sabor com a aparência. Eles estão associados no limão. Pelo menos o termo "associaçốes de palavras" está nomeado corretamente. Se dizemos "lar" quando alguém diz "casa", não é porque nós associamos as duas palavras, mas porque elas estão associadas no uso diário da língua. Associação cognitiva é uma invenção. Mesmo que fosse real, ela não avançaria na direção de uma explicação mais do que as contingências nas quais é modelada.

Outro exemplo é abstração. Considere um experimento simples. Um pombo faminto pode bicar qualquer um de uma série de painéis com nomes de cores - "branco", "vermelho", "azul”, e assim por diante, e as bicadas são reforçadas com pequenas quantidades de comida. Qualquer um de um conjunto de objetos - blocos, livros, flores, animais de brinquedo, etc. - podem ser vistos em um espaço adjacente. As seguintes contingências são então arranjadas: sem- pre que o objeto apresentado for branco, não importando a forma ou o tamanho, apenas bicadas no painel marcado "branco" serão reforçadas, quando o objeto for vermelho, apenas bicadas no painel marcado de "vermelho" serão reforçadas, e assim por diante. Sob estas condições o pombo eventualmente bica o painel marcado "branco" quando o objeto é branco, o painel marcado "vermelho" quando o objeto é vermelho e assim por diante; as crianças são ensinadas a nomear cores com contingências similares e nós possuímos repertórios comparáveis, sustentados pelas práticas reforçadoras de nossos ambientes verbais.

Mas o que se diz sobre o que está se passando na mente? Karl Popper (1957) propôs o problema clássico desta forma. "Podemos dizer ou que (1) o termo universal "branco" é um rótulo aposto a um conjunto de coisas ou que (2) reunimos o conjunto porque as coisas compartilham uma propriedade intrínseca de "brancura"." Popper diz que a distinção é importante; os cientistas naturalistas podem optar pela primeira posição, mas os cientistas sociais devem tomar a segunda. Devemos dizer, então, que o pombo está atribuindo um termo universal a um conjunto de coisas ou reunindo um conjunto de coisas porque elas compartilham uma propriedade intrínseca? Claramente, é o experimentador e não o pombo quem "vincula" a chave branca aos objetos apresentados e quem reúne o conjunto de objetos ao qual um evento reforçador particular é tornado contingente. Será que não deveríamos simplesmente atribuir o comportamento às contingências experimentais? E se assim for, porque não fazer o mesmo para crianças e nós mesmos? O comportamento fica sob controle de estímulos sob certas contingências de reforçamento. Contingências especiais 
mantidas por comunidades verbais produzem "abstraçôes". Nós vinculamos, sim, rótulos físicos a coisas físicas e agrupamos objetos físicos de acordo com propriedades rotuladas, mas processos cognitivos comparáveis são invenções que, mesmo se reais, não estariam mais próximas de uma explicação do que as contingências externas.

Outra explicação cognitiva dos mesmos dados afirmaria que uma pessoa, como também um pombo, forma uma idéia abstrata ou desenvolve um conceito de cor. O desenvolvimento de conceitos é um campo cognitivo especialmente popular. (A metáfora horticultural minimiza as contribuições do ambiente. Nós podemos acelerar o crescimento da mente, mas não somos mais responsáveis por sua característica final do que os fazendeiros pela característica das frutas e vegetais que eles tão cuidadosamente nutrem). A visão de cores é parte da dotação genética da maioria das pessoas e ela se desenvolve ou cresce no sentido fisiológico, possivelmente também em algum grau após o nascimento. No entanto, a maioria dos estímulos adquire controle por sua posição nas contingências de reforçamento. À medida que as contingências se tornam mais complexas, elas modelam e mantém comportamentos mais complexos. É o ambiente que se desenvolve, não uma propriedade mental ou cognitiva.

Uma passagem de uma discussão recente do desenvolvimento da identidade sexual em uma criança poderia ser transcrita como se segue: "A criança forma um conceito baseada no que ela observou e ouviu dizer sobre o que significa ser um menino ou uma menina." (O comportamento de uma criança é afetado por aquilo que ela observou e lhe contaram sobre ser um menino ou uma menina). "Este conceito é super simplificado, exagera- do e estereotipado." (As contingências afetando o comportamento são simplificadas e exageradas e envolvem comportamento estereotipado da parte dos pais e outras pessoas). “'A medida que a criança se desenvolve cognitivamente, seus conceitos e, consequentemente suas atividades se tornam mais sofisticadas e realistas." (À medida a criança fica mais velha, as contingências se tornam mais sutis e mais intimamente relacionadas ao sexo real da criança). As crianças não saem por aí formando conceitos de sua identidade sexual e "consequentemente" se comportando de maneiras especiais; elas mudam seu comportamento vagarosamente à medida que as pessoas mudam as maneiras com que as tratam por causa do seu sexo. O comportamento muda porque as contingências mudam, não porque uma entidade mental chamada conceito se desenvolve.

Muitos termos mentalistas ou cognitivos não se referem às contingências apenas, mas ao comportamento que elas geram. Termos como "mente', "desejo" e "pensamento" são muitas vezes sinônimos de "comportamento". Um historiador escreve: "Prevalece o que poderia se chamar de estagnação do pensamento, como se a mente, exausta após erigir a estrutura espiritual da Idade Média, tivesse se afundado na inércia”. Exaustão é uma metáfora plausível quando um período estagnado se segue a um ativo, mas foi o comportamento que se tornou estagnado e inerte, presumivelmente porque as contingências mudaram. Certas condições sociais ("a estrutura espiritual da Idade Média”) tornaram as pessoas ativas. Um segundo conjunto de condições, possivelmente produzido pelo próprio comportamento gerado pelo primeiro, as tornou muito menos ativas. Para compreender o 
que realmente aconteceu, deveríamos saber por que as contingências mudaram não porque o pensamento se tornou estagnado ou inerte.

O comportamento é internalizado como vida mental quando é muito sutil para ser observado por outros - quando, como dizemos, é encoberto. Um escritor apontou que "o maestro de uma orquestra mantém uma mesma cadência de acordo com o ritmo interno, e ele pode dividir aquela cadência ao meio várias vezes com uma precisão que rivaliza a de qualquer instrumento mecânico." Mas existe um ritmo interno? Manter a cadência é um comportamento. Partes do corpo servem com freqüência como pêndulos úteis na determinação de velocidade, como quando o músico amador marca o compasso com o pé ou como o tocador de rock com todo o corpo, mas outros comportamentos bem cadenciados precisam ser aprendidos. O maestro marca o compasso de forma estável porque ele aprendeu a fazê-lo assim sob contingências de reforçamento bastante precisas. $\mathrm{O}$ comportamento pode ser reduzido em escala até que não seja visível a outros. Ainda assim é sentido pelo maestro, mas é uma sensação de comportamento, não de tempo. A história do "desenvolvimento de um sentido de tempo pelo homem" ao longo dos séculos não é uma questão de crescimento cognitivo, mas da invenção de calendários, relógios e meios de manter registros - em outras palavras, de um ambiente que "guarda tempo".

Quando um historiador relata que em um dado período "uma classe governante saudável, brilhante e tradicional perdeu sua vontade" ele está apenas relatando que ela parou de agir como uma classe governante saudável, brilhante e tradicional. $\mathrm{O}$ termo vontade sugere mudanças mais profundas, mas elas não são identificadas. Elas não poderiam ter sido mudanças em pes- soas em particular, uma vez que o período durou mais que o tempo de uma vida. O que mudou foram, presumivelmente, as condições que afetavam o comportamento dos membros da classe. Talvez tenham perdido seu dinheiro, talvez classes competidoras tenham se tornado mais poderosas.

Sentimentos, ou as condições corporais que sentimos, são comumente tomadas como as causas do comportamento. Nós vamos dar uma volta porque "nos sentimos a fim de ir". É surpreendente quão freqüentemente a futilidade de tal explicação é reconhecida. Um biólogo de renome, C.H. Waddington (1974), revisando um livro de Tinbergen, escreveu assim:

\begin{abstract}
"Não fica claro até que ponto ele (Tinbergen) concordaria com o argumento de uma das discussões críticas mais perceptivas da etologia feita por Suzanne Sanger, que argumenta que cada passo em uma estrutura complexa do comportamento é controlada, não por um conjunto hierárquico de centros neuronais, mas pelos sentimentos imediatos do animal. $\mathrm{O}$ animal, ela afirma, dá o próximo passo na seqüência não para aproximar-se de um objetivo útil, ou mesmo como um movimento em direção a uma consumação agradável, mas porque ele se sente a fim de fazer aquilo naquele momento.”
\end{abstract}

Evidentemente, o próprio Waddington concorda de modo parcial com esta "visão perceptiva."

Mas suponha que Langer esteja certa. Suponha que os animais simplesmente fazem o que eles estão a fim de fazer. Qual é o próximo passo para explicar seu comportamento? Claramente, uma ciência do comportamento dos animais deveria ser substituída ou complementada por uma ciência dos sentimen- 
tos dos animais. Ela seria tão extensa quanto a ciência do comportamento, porque haveria presumivelmente uma sensação para cada ato. Mas os sentimentos são mais difíceis de identificar e descrever do que os comportamentos atribuíveis a eles, e nós teríamos abandonado o objeto de estudos objetivo em favor de um de status dúbio, acessível apenas por meio dos canais necessariamente defeituosos da introspecção. As contingências seriam as mesmas. Os sentimentos e o comportamento teriam as mesmas causas.

Um político Britânico afirmou recentemente que a chave para o crime nas ruas era a frustração. Os jovens assaltam e roubam porque se sentem frustrados. Mas porque eles se sentem frustrados? Uma possível razão é o fato de estarem desempregados ou porque eles não têm a educação necessária para conseguir empregos ou porque não existem empregos disponíveis. Portanto, para resolver o problema do crime nas ruas, devemos mudar as escolas e a economia. Mas que função a frustração tem nisso tudo? Será o caso de que quando alguém não pode obter um emprego se sente frustrado e que quando alguém se sente frustrado assalta e rouba, ou será simplesmente o caso de que quando alguém não pode ganhar dinheiro esse alguém mais provavelmente irá roubá-lo - e possivelmente experimentar uma condição corporal chamada frustração?

Considerando que muitos eventos que devem ser levados em conta ao se explicar o comportamento estão associados com estados corporais que podem ser sentidos, o que é sentido pode servir como uma pista para as contingências. Mas os sentimentos não são as contingências e não as podem substituir como causas.

Por sua própria natureza o comportamento operante encoraja a invenção de processos mentais ou cognitivos que se diz iniciarem a ação. No reflexo, condicionado ou incondicionado, há uma causa anterior conspícua. Algo dispara a resposta. Mas o comportamento que tenha sido reforçado positivamente ocorre em ocasiões em que, ainda que predisponham, nunca compelem sua ocorrência. $\mathrm{O}$ comportamento parece começar de repente, sem aviso prévio, como se fosse gerado espontaneamente. Daí a invenção de entidades cognitivas tais como intenção, propósito ou desejo. Os mesmos problemas foram debatidos com relação à Teoria da Evolução e pela mesma razão: a seleção é um modo causal especial não facilmente observável. Porque as circunstâncias controladoras que repousam na história de reforçamento de um organismo são obscuras, o substituto mental tem sua chance. Sob reforçamento positivo, dizemos que fazemos o que estamos livres para fazer; daí a noção de livre arbítrio como uma condição iniciadora. (Eu acho que foi Jonathan Edwards quem disse que acreditamos em livre arbítrio porque sabemos sobre nossos comportamentos, mas não sobre as suas causas).

Quando não sabemos por que uma pessoa faz uma coisa ao invés de outra, nós dizemos que elas "escolhem" ou "tomam decisões". Escolher, originalmente significava examinar, escrutinizar cuidadosamente ou testar. Etimologicamente, decidir significa cortar outras possibilidades, mover-se em uma direção da qual não há retorno. Escolher e decidir são, então, formas conspícuas de comportamento, mas psicólogos cognitivistas, não obstante, inventaram equivalentes internos. Anatole Rapaport (1973) coloca dessa forma: "Em um experimento psicológico, um sujeito tem que escolher entre alternativas e selecionar uma alternativa entre outras". Quando tal ocorre, ele 
diz: "o senso comum sugere que ele seja guiado por uma preferência”. O senso comum de fato sugere isso, e também o fazem os psicólogos cognitivistas, mas onde está e o que é uma preferência? É algo mais do que uma tendência a fazer uma coisa ao invés de outra? Quando não podemos dizer de onde vem o vento e para onde vai, nós dizemos que ele "sopra caprichosamente" (ao pé da letra: "sopra para onde se inclina a soprar"). E o senso comum, senão a psicologia cognitivista, credita isso à preferência. (A propósito, inclinar-se é um exemplo de termo com um referencial físico usado para se referir a um processo mental. Significa, naturalmente, inclinar-se, como quando o navio balança. E uma vez que as coisas usualmente caem na direção em que se inclinam, nós dizemos que as pessoas se inclinam em favor de um candidato em uma eleição como uma forma grosseira de predizer como elas vão votar. A mesma metáfora se encontra em "inclinação"; nós estamos "inclinados a votar em X. Mas isto não significa que tenhamos tendências e inclinações internas que afetam o nosso comportamento).

"Intenção" é um termo bastante similar, que só significa antecipação. A versão cognitiva é uma questão crítica na lingüística atual. A intenção do locutor deve ser considerada? Em uma análise operante o comportamento é determinado pelas conseqüências que o seguem em um dado ambiente verbal, e é de conseqüências que os psicólogos cognitivistas estão realmente falando quando falam de intenções. Todo comportamento operante "antecipa" um futuro, mesmo que as únicas conseqüências responsáveis por sua força já tenham ocorrido. Eu vou a um bebedouro "com a intenção" de tomar um pouco d'água no sentido de que eu vou porque no passado eu pude beber quando fui lá. (Eu posso ir pela primeira vez seguindo indicações, mas esta não é uma exceção; é um exemplo de comportamento governado por regras, do qual falaremos mais tarde).

Já chega de internalização cognitiva de contingências de reforçamento e invenção de causas cognitivas do comportamento. Bem mais nociva para uma análise efetiva é a internalização do ambiente. Os gregos inventaram a mente para explicar como o mundo real podia ser conhecido. Para eles, conhecer significava estar familiarizado com, ser íntimo de. O próprio termo cogniçãa está relacionado a coito, no sentido bíblico em que se diz que um homem conheceu uma mulher. Não tendo uma física adequada do som e da luz, nem qualquer química do paladar e do olfato, os gregos não podiam entender como o mundo fora do corpo, possivelmente a alguma distância, podia ser conhecido. Devia haver cópias internas. Daí os equivalentes cognitivos do mundo real.

A distinção entre realidade e experiência consciente tem sido feita tão freqüentemente que agora parece auto-evidente. Fred Attneave (1974) escreveu recentemente que "a afirmação de que o mundo que conhecemos é uma representação é, em minha opinião, um truísmo - não há realmente nenhum jeito de estar errado". Mas existem pelo menos duas maneiras de entender o que se quer dizer. Se a afirmação quer dizer que nós podemos apenas conhecer representaçôes do mundo externo, isto é um "truísmo" apenas se não somos nossos corpos, mas habitantes localizados em algum lugar dentro dele. Nossos corpos estão em contato com o mundo real e podem responder a ele diretamente, mas se estamos ocultos em algum ponto na cabeça, devemos nos satisfazer com representaçóes.

Outra significação possível é a de que conhecer seja o próprio processo de construir có- 
pias mentais das coisas reais, mas se for esse o caso, como conhecemos as cópias? Fazemos cópias delas? Será infinita essa regressão?

Alguns psicólogos cognitivistas reconhecem que conhecer é ação, mas tentam defender seu ponto de vista apelando para outros equivalentes mentais. $\mathrm{O}$ conhecimento é entendido como "um sistema de proposiçôes". De acordo com um escritor, "quando usamos a palavra "ver" nos referimos a uma ponte entre um padrão de estimulação sensorial e o conhecimento que é proposicional. Mas "proposicional” é simplesmente um eufemismo de “comportamental”, e a "ponte" é entre estímulos e comportamento e foi construída quando os estímulos eram partes das contingências.

Teorias representacionais do conhecimento são construídas a partir do comportamento prático. Nós fazemos sim cópias das coisas. Nós construímos trabalhos artísticos de representação, porque olhar para eles é reforçado de forma bastante similar a olhar para o que eles representam. Nós fazemos mapas, porque o nosso comportamento de segui-los é reforçado quando chegamos ao nosso destino no território mapeado. Mas existem equivalentes internos? Quando devaneamos, primeiro construímos cópias dos episódios reforçadores que então vemos ou simplesmente vemos as coisas de novo? Quando aprendemos a andar em um determinado território, construímos mapas cognitivos que então seguimos, ou seguimos o território? Se nós seguimos o mapa cognitivo, devemos aprender a fazer isso, e tal aprendizagem irá requerer um mapa do mapa? Não há nenhuma evidência da construção mental de imagens para serem olhadas ou mapas para serem seguidos. $\mathrm{O}$ corpo responde ao mundo no ponto de contato; fazer cópias seria um desperdício de tempo.
Reconhecimento é um termo chave na teoria cognitiva, e ele cobre um extenso campo. Ele é freqüentemente contrastado com percepção. Dizemos que somos capazes de ver que existem três pontos em um cartão, mas apenas sabemos que existem treze após contá-los, embora contar seja uma forma de comportamento. Depois de notar que uma espiral pode ser vista como sendo contínua, mas que isso só se descobre rastreando-a, Bela Julesz (1975) disse que "qualquer tarefa visual que não pode ser desempenhada espontaneamente, sem esforço ou deliberação, pode ser considerada como uma tarefa cognitiva ao invés de perceptual," embora todos os passos naquele exemplo sejam claramente comportamentais.

"Saber como fazer alguma coisa" é um equivalente interno de comportamento em sua relação com as contingências. Uma criança aprende a andar de bicicleta e então se diz que ela possui conhecimento de como manobrá-la. O comportamento da criança foi mudado pelas contingências de reforçamento mantidas por bicicletas; a criança não toma posse das contingências.

Falar em saber acerca de coisas é também construir um equivalente interno das contingências. Nós assistimos a um jogo de futebol e dizemos então possuir o conhecimento do que aconteceu. Nós lemos um livro e dizemos saber do que se trata. $\mathrm{O}$ jogo e o livro estão, de alguma forma, "representados" em nossas mentes: nós estamos "de posse de certos fatos". Mas a evidência é simplesmente de que nós podemos descrever o que aconteceu no jogo e relatar sobre o que o livro versava. Nosso comportamento mudou, mas não há nenhuma evidência de que tenhamos adquirido conhecimento. Estar "de posse de fatos" não é conter os fatos dentro de nós mesmos, mas ter sido afetado por eles. 
Posse de conhecimento implica em armazenamento, um campo em que os psicólogos cognitivistas construíram um grande número de equivalentes mentais do comportamento. Diz-se que o organismo internaliza e armazena o ambiente, possivelmente de alguma forma já processada. Suponhamos que uma menina tenha visto uma gravura ontem e hoje, quando solicitada a descrevê-la, o faz. O que aconteceu? Uma resposta tradicional seria mais ou menos assim: quando ela viu a gravura ontem ela formou uma cópia em sua mente (a qual, de fato, foi tudo o que ela viu). Ela codificou a gravura de forma adequada e armazenou-a em sua memória, onde permanece até hoje. Hoje quando solicitada a descrever a figura, ela procurou em sua memória, recuperou a cópia codificada e converteu-a em algo semelhante à gravura original, para a qual ela então olhou e descreveu. A explicação é baseada no armazenamento físico de memorandos. Fazemos cópias e outros registros, e respondemos a eles. Mas fazemos qualquer coisa desse tipo em nossas mentes?

Se alguma coisa é "armazenada", é comportamento. Nós falamos de "aquisição" de comportamento, mas de que forma ele é possuído? Onde está o comportamento quando o organismo não está se comportando? Onde os comportamentos que exibo quando estou ouvindo música, jantando, conversando com um amigo, dando um passeio matinal ou coçando uma picada estão no presente momento e que forma eles têm? Um psicólogo cognitivista disse que o comportamento verbal é armazenado como "memórias léxicas". O comportamento verbal deixa freqüentemente registros públicos que podem ser armazenados em estantes e livrarias e a metáfora da armazenagem é, portanto, particularmente plausível. Mas essa expressão é mais útil do que dizer que o meu comportamento ao jantar é armazenado como memórias prandiais, ou coçar-se como memória pruriente? Os fatos observados são bastante simples: eu adquiro um repertório de comportamento, partes do qual eu exibo em ocasiōes apropriadas. A metáfora de armazenagem e recuperação vai bem além desses fatos.

O computador, juntamente com a teoria da informação planejada para lidar com sistemas físicos, fez da metáfora da entradaarmazenamento-recuperação-saída um modismo. O esforço para fazer máquinas que pensam como pessoas teve como efeito apoiar as teorias que sugerem que pessoas pensam como máquinas. A mente foi recentemente definida como “o sistema de organizações e estruturas pertencentes a um indivíduo que processa entradas... e provê saídas para os vários subsistemas e o mundo." Mas organizaçōes e estruturas do quê? (A metáfora ganha força pelo modo como descarta problemas trabalhosos. Falando de entrada se pode esquecer todo o trabalho da psicologia sensorial e da fisiologia; falando de saída se esquece de todo o problema de descrever e analisar a ação; e falando de armazenamento e recuperação da informação pode-se esquivar de todos os problemas difíceis relacionados a como os organismos são efetivamente mudados pelo contato com seus ambientes e como tais mudanças sobrevivem.).

Freqüentemente se diz que os dados sensoriais são armazenados como imagem, da mesma forma que se diz que as imagens representam o mundo real. Uma vez dentro, elas são manipuladas de acordo com os propósitos cognitivos. Há um experimento conhecido sobre generalização de cor em que um pombo bica um disco de, digamos, luz verde, e o comportamento é reforçado em esquema de inter- 
valo variável. Quando se desenvolve uma taxa estável de respostas não se dá mais nenhum reforçador e a cor do disco é mudada. $\mathrm{O}$ pombo responde a uma outra cor com uma taxa que depende de quanto ela difere da cor original; cores bastante semelhantes evocam taxas bastante altas, cores muito diferentes taxas baixas. Um psicólogo cognitivista poderia explicar o problema desta forma: o pombo percebe uma cor nova (como "entrada"), recupera a cor original da memória, onde ela estava armazenada de alguma forma, põe as duas imagens coloridas lado a lado, de forma que possam ser facilmente comparadas e depois de avaliar a diferença, responde com a taxa apropriada. Mas que vantagem se ganha indo de um pombo que responde a diferentes cores em um disco para um pombo interno que responde às imagens coloridas em sua mente? O fato simples é que por causa de uma história conhecida de reforçamento, cores diferentes controlam taxas diferentes.

A metáfora cognitiva está baseada em comportamento que ocorre no mundo real. Nós guardamos exemplares de coisas e as retomamos e comparamos com outros exemplares. Nós os comparamos no sentido literal de colocá-los lado a lado, para tornar as diferenças mais óbvias. E respondemos a diferentes coisas de diferentes formas. Mas isso é tudo, todo o campo de processamento de informação pode ser reformulado como mudança no controle exercido pelos estímulos.

O armazenamento do conhecimento factual levanta outro problema. Quando eu aprendo, digamos, a separar um quebra-cabeça por partes, parece improvável que eu armazene meu conhecimento de como fazê-lo a partir de uma cópia do quebra-cabeça ou das contingências que o quebra-cabeça apresenta para quem tenta resolvê-lo. Contrariamente, a teoria cognitiva sustenta que eu armazeno uma regra. Regras são muito usadas como substitutos mentais do comportamento, em parte porque elas podem ser memorizadas e, portanto, "possuídas", mas há uma diferença importante entre regras e as contingências que elas descrevem. Regras podem ser internalizadas no sentido de que podemos dizê-las a nós mesmos, mas ao fazê-lo, nós não internalizamos as contingências.

Eu posso aprender a resolver o quebracabeça de duas maneiras. Posso mexer com as peças para lá e para cá até conseguir uma resposta que as separe. $\mathrm{O}$ comportamento será fortalecido, e se eu fizer a mesma coisa várias vezes, eventualmente serei capaz de separar as peças rapidamente. Meu comportamento foi modelado e mantido por seus efeitos sobre as peças. Eu posso, por outro lado, simplesmente seguir as instruções impressas que vêm com o quebra-cabeça. As instruções descrevem o comportamento que separa as peças, e se eu já tiver aprendido a seguir instruçóes, posso evitar o processo possivelmente longo de ter meu comportamento modelado pelas contingências.

Instruções são regras. Assim como conselhos, avisos, máximas, provérbios e leis científicas e governamentais, elas são parte importante de uma cultura, permitindo às pessoas tirar proveito da experiência dos outros. Aqueles que adquiriram o comportamento pela exposição às contingências descrevem as contingências, e outros, então, evitam se expor comportando-se das formas descritas. Mas os psicólogos cognitivistas defendem que algo do mesmo tipo ocorre internamente quando as pessoas aprendem diretamente por meio das contingências. Diz-se que elas descobrem regras que, então, elas mesmas seguem. Mas as regras não estão nas contingências, nem pre- 
cisam ser conhecidas por aqueles que adquirem comportamento sob exposição a estas. (Por sorte nossa isto é assim, uma vez que regras são produtos verbais que surgiram muito tarde na evolução da espécie).

A distinção entre e regras e contingências é realmente importante no campo do comportamento verbal. Crianças aprendem a falar mediante o contato com comunidades verbais, possivelmente sem instrução. Algumas respostas verbais são efetivas e outras não, e durante um período de tempo mais e mais comportamento é modelado e mantido. As contingências que tem esse efeito podem ser analisadas. Uma resposta verbal "significa" algo no sentido de que o locutor está sob controle de circunstâncias particulares; um estímulo verbal "significa" algo no sentido de que o ouvinte responde a ele de maneiras particulares. A comunidade verbal mantém contingências onde respostas que ocorrem em ocasiōes particulares servem como estímulos úteis para ouvintes que, então, se comportam apropriadamente às ocasiōes.

Relações mais complexas entre os comportamentos do locutor e do ouvinte caem no campo da sintaxe e da gramática. Até a época dos gregos, parece que ninguém sabia que havia regras de gramática, ainda que as pessoas falassem gramaticalmente no sentido em que se comportavam efetivamente sob as contingências mantidas pelas comunidades verbais, assim como as crianças de hoje aprendem a falar sem a necessidade de regras para seguir. Mas os psicólogos cognitivistas insistem que falantes e ouvintes devem descobrir as regras por si próprios. Uma autoridade inclusive, definiu falar como "engajar-se em uma forma de comportamento intencional governado por regras". Mas não há evidência de que regras tenham qualquer participação no comportamento do falan- te comum. Usando um dicionário e uma gramática nós podemos compor sentenças aceitáveis em uma língua que não falamos, e podemos ocasionalmente consultar um dicionário ou uma gramática ao falar nossa própria língua, mas mesmo assim raramente falamos aplicando regras. Nós falamos porque nosso comportamento é modelado e mantido pelas práticas de uma comunidade verbal.

Tendo mudado o ambiente para dentro da cabeça na forma de experiência consciente e o comportamento na forma de intenção, desejos, e escolhas, e tendo armazenado os efeitos das contingências de reforçamento como conhecimento e regras, os psicólogos cognitivistas colocam tudo isso junto para compor um simulacro interno do organismo, um tipo de doppleganger, nada diferente do homúnculo clássico, cujo comportamento é o objeto de estudo do que Piaget e outros chamaram de "behaviorismo subjetivo". O aparato mental estudado pela psicologia cognitivista é simplesmente uma versão bastante grosseira das contingências de reforçamento e seus efeitos.

Todo processo chamado cognitivo tem um modelo físico. Nós associamos coisas colocandoas juntas. Nós armazenamos memorandos e recuperamos para uso posterior. Nós comparamos coisas colocando-as lado a lado para enfatizar as diferenças. Nós discriminamos coisas umas das outras separando-as e tratando-as de diferentes maneiras. Nós identificamos objetos retirandoos do ambiente confuso. Nós abstraímos conjuntos de itens de arranjos complexos. Nós descrevemos contingências de reforçamento em regras. Essas são as ações das pessoas reais. É apenas no mundo fantasioso de uma pessoa interna que elas se tornam processos mentais.

A própria rapidez com que os processos cognitivos são inventados para explicar o com- 
portamento deveria suscitar suspeita. Molière fez uma piada de um exemplo médico há mais de três séculos atrás. "Doutores estudados me perguntaram por que razão o ópio faz alguém dormir, ao que eu respondi que há nele uma virtude soporífera cuja natureza é a de aquietar os sentidos." O personagem de Molière poderia ter citado evidências de introspecção, invocando um efeito colateral da droga, dizendo: "Ao que eu respondi que o ópio faz a pessoa sentir sono". Mas a virtude soporífera em si é totalmente uma invenção, e não deixa de ter paralelos atuais.

Recentemente ocorreu na Europa uma conferência sobre o assunto da criatividade científica. Um relato publicado na Science (1974) começa revelando que mais de noventa por cento da inovação científica foi obtida por menos de dez por cento de todos os cientistas. A sentença seguinte poderia ser parafraseada desta forma: "Os doutores estudados me perguntaram pela causa e a razão por que isso seria assim, ao que eu respondi que é porque apenas uns poucos cientistas possuem criatividade." Similarmente, os doutores estudados me perguntaram pela causa e a razão porque as crianças aprendem a falar com grande rapidez, ao que eu respondi que isso se dá porque elas possuem competência lingüística. "As audiências de Molière cairiam no riso".

Os psicólogos cognitivistas têm duas respostas para a acusação de que o aparato mental é uma metáfora ou um construto. Uma é que os processos cognitivos são conhecidos via introspecção. Todos os seres pensantes não sabem que pensam? E se os behavioristas dizem que não, será que eles não estão ou demonstrando uma mentalidade de ordem inferior ou agindo de má fé em defesa de sua posição? Ninguém dúvida que o comportamento envolve processos internos; a questão é quão bem eles podem ser conhecidos via introspecção. Como eu argumentei noutra ocasião, autoconhecimento ou consciência se tornaram possíveis apenas quando a espécie adquiriu comportamento verbal, e isso foi muito tarde em sua história. $\mathrm{O}$ único sistema nervoso até então disponível se desenvolveu por outros propósitos e não fazia contato com as atividades fisiológicas mais importantes. Aqueles que se vêem pensando vêem pouco mais do que seu comportamento perceptual e motor, aberto e encoberto. Poder-se-ia dizer que eles observam os resultados de "processos cognitivos", mas não os próprios processos - um "fluxo de consciência” mas não o que causa o fluxo, a "imagem de um limão" mas não o ato de associar aparência com sabor, seu uso de um termo abstrato mas não o processo de abstração, um nome lembrado mas não sua recuperação da memória, e assim por diante. Pela introspecção nós não observamos os processos fisiológicos por meio dos quais o comportamento é modelado e mantido pelas contingências de reforçamento.

Mas os fisiologistas os observam e os psicólogos cognitivistas apontam para as semelhanças que sugerem que eles e os fisiologistas estão falando das mesmas coisas. O próprio fato de que os processos cognitivos se dão dentro do organismo sugere que a abordagem cognitiva está mais próxima da fisiologia do que as contingências de reforçamento estudadas por aqueles que analisam o comportamento. Mas se os processos cognitivos são moldados simplesmente com base nas contingências ambientais, o fato deles serem designados para um espaço dentro da pele não os traz mais próximos de uma abordagem fisiológica. Pelo contrário, a fascinação com uma vida interior imaginada tem levado à negligência dos fatos observados. Os 
construtos cognitivos dão aos fisiologistas uma explicação enganosa do que deveriam encontrar dentro do organismo.

Em suma, então, eu não sou um psicólogo cognitivista por várias razões. Não vejo qualquer evidência de um mundo interior de vida mental que se relacione quer com uma análise do comportamento como uma função de forças ambientais quer com a fisiologia do sistema nervoso. As respectivas ciências do comportamento e a fisiologia avançarão mais rapidamente se seus domínios forem corretamente definidos e analisados.

$\mathrm{Eu}$ estou igualmente preocupado com as conseqüências práticas. $\mathrm{O}$ apelo para estados e processos cognitivos é um desvio de atenção que bem pode ser responsável por muito de nossa falha em resolver nossos problemas. Nós precisamos mudar nosso comportamento e só podemos fazê-lo mudando nosso ambiente físico e social. Nós escolhemos o caminho errado já de início, quando fazemos a suposição de que nossa meta é mudar "mentes e coraçōes de mulheres e homens" ao invés do mundo em que eles vivem.

\section{REFERÊNCIAS}

Attneave, F. (1974). How do you know? American Psychologist, 29, 493-499.

Julesz, B., (1975). Experiments in the visual perception of texture. Scientific American, 232(4), 34-43.

Popper, K. 1957. The poverty of historicism. London: Routledge \& Kagan Paul.

Rapoport, A. (1973). Experimental games and their uses in psychology. Morristown, NJ: General Learning Press.

Waddington, C. H. (1974). New York Review, February, 3, 1974.

Tradução recebida em 29 de agosto de 2007 